\title{
The Learners' User Classes in the TERENCE Adaptive Learning System
}

\author{
T. Di Mascio, P. Vittorini \\ DIEI - MISP \\ University of L'Aquila \\ L'Aquila, Italy \\ tania.dimascio@univaq.it \\ pierpaolo.vittorini@cc.univaq.it
}

\author{
R. Gennari, A. Melonio \\ $K R D B$ \\ Free University of Bozen \\ Bozen, Italy \\ gennari@inf.unibz.it
}

\author{
F. De La Prieta \\ Computers and Automation Dep. \\ University of Salamanca \\ 37008, Salamanca, Spain \\ fer@usal.es
}

\author{
M. Alrifai \\ L3S Research Center \\ 30167 Hannover, Germany \\ alrifai@l3s.de
}

\begin{abstract}
Nowadays, circa $10 \%$ of $7-11$ olds turn out to be poor comprehenders: they demonstrate text comprehension difficulties, related to inference making, despite proficiency in low-level cognitive skills like word reading. To improve the reading comprehension of these children, TERENCE, a technology enhanced learning project, aims at stimulating inference-making about stories. In order to design and develop the TERENCE system, we use a user centred design approach that requires an in depth study of the system's main end-users, namely, its learners and educators. This paper reports on the specification of the user classes for the TERENCE learners by means of user-centred design field studies, the resulting global system architecture, and an example use case of the system, with few related GUI's snapshots.
\end{abstract}

Keywords-KR; UCD; EBD; TEL; user-classes; architecture; use-cases

\section{INTRODUCTION}

Nowadays, more and more 7-11 olds turn out to be poor (text) comprehenders: they demonstrate difficulties in deep text comprehension, despite well developed low-level cognitive skills. TERENCE, part of an FP7 ICT TEL project, builds an adaptive learning system (ALS) [3] for improving the text comprehension of such children. The conceptual model of the TERENCE ALS is described in [1], [2]. In particular, the domain model structures the material of the ALS, namely, stories and games for improving text comprehension. The user model structures the information concerning the end users of the system, that are: learners, that is, 7-11 old children; educators, namely, teachers and parents; experts, that is, the end users providing material for the system, and that work with the back-end of the system (e.g., psychologists, linguists).

To guide the design and development of the TERENCE ALS, we adopted the user centred design (UCD) [6]. In an UCD approach, potential users of the system are first classified under design according to the expected usage of the system: these are the user types, based on on the literature or documentation studies. Then types are refined into user classes, which are based on the analysis of the context of use and the user requirements.

The first goal of this paper is to briefly document the specification of learners' user classes resulting from the analysis of the context of use and user requirements analysis; in particular, Sect. II reports on the latest field study for such analysis, ending with personas.

The second major goal of this document is to show how user classes lead to the specification of the current architecture of the system, through personas and use cases. Sect. III explains and exemplifies the former, whereas Sect. Sect. IV does the latter. Sect. $\square$ concludes the paper and the on-going work resulting from this.

\section{The User Classes Building Process}

Hereby, we describe the specification of user classes for the learners' type of TERENCE. The data gathering hereby reported was done through a field study conducted in Italy in the middle of 2011, based on field studies run at the beginning of 2011, in turn based on brainstorming meetings, inquiries with experts and the study of documentation for the TERENCE project. More details concerning them are in [9], [11], [10]. Following UCD practices, see e.g., [7] and [8], we conducted the TERENCE field studies with user-based criteria [10]. The experiment design of the latest field study, with the users participating in the experiment and their teaching, are reported in Subss. III-A. The experiment execution is in Subss. II-B The classes resulting from the analysis are in Subss. II-C One of the related personas is in Subss. II-D.

\section{A. Experiment design and Users}

Using conceptual maps, we designed specific user tasks for the study in order to analyse and refine the users' characteristics. For the reader's convenience, Tab. I] III IV, and $\mathrm{V}$ present a detailed overview of these tasks and of the methods used to gather the data. The experiments involved 18 teachers and 282 learners (7-11 years old). Consider that 8 olds belong to Class 3. Tabs. VI and VII present the user involvement. Schools were informed about the field study through preliminary meetings of the planning stage. In particular, during the meeting with teachers, all teachers asked to administer the same test to all the children in the classroom, independently of their text comprehension skills, for ethical issues. 
Table I

EXTRACURRICULAR ACTIVITIES

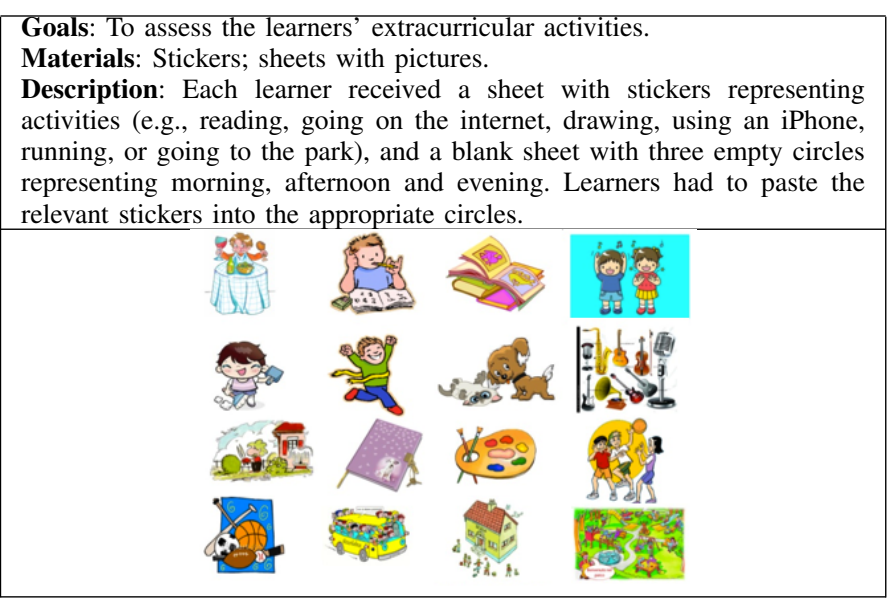

Table II

TECHNOLOGY USE AND READING.

Goals: In this task, learners were asked about their use of technology and about their reading activities. More specifically, we wanted to gather data about the use of TV, computer, mobile phone and about reading.

Materials: Four sheets with conceptual maps of an activity.

Description: Each learner received four sheets, one for each activity (TV, computer, mobile phone, reading). Each sheet contained a picture of the activity in the centre. The picture was accompanied by six questions: (1) Who do you use this with?, (2) When do you use it?, (3) What do you use it for?, (4) Where do you use it?, (5) Why do you use it?, and (6) how often do you use it?

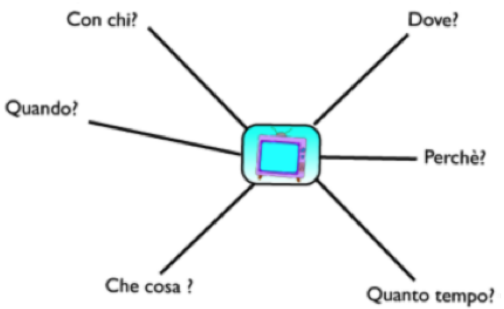

Table III

GAMES

Goals: In this task, learners were asked about their favourite consoles and game consoles.

Materials: Stickers; sheets.

Description: Learners received sheets with stickers representing game consoles (e.g., Wii, XBox) and a conceptual map. Learners were asked to put the sticker of their favourite console in the centre of the map, and to answer the questions on the map ((1) Who do you use this with?, (2) When do you use this?, (3) Which games do you like?, (4) Where do you play this?, (5) Why do you play this?)

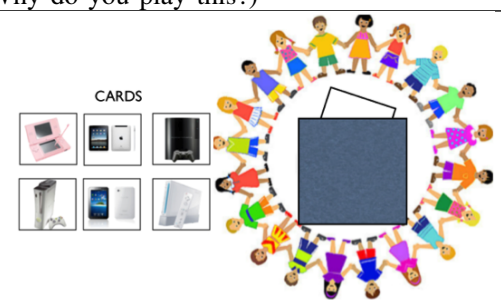

Table IV

INTERACTION WITH PARENTS.

Goals: To gather information about the interaction between learners and their parents.

Materials: Maps.

Description: Learners received two sheets, one with a picture of "mom" in the middle, the other one with a picture of "dad". They were asked to list six (or less or more) activities they often do together with their mom or dad

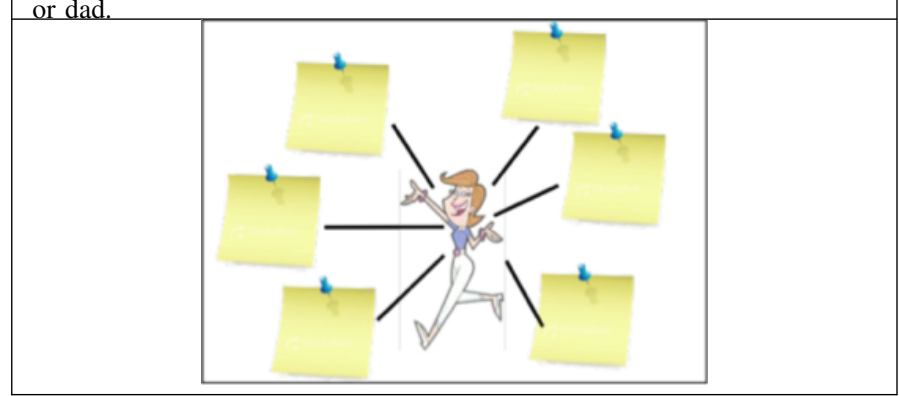

Table V

HOMEWORK.

Goals: To gather information about how learners make their homework Materials: A cardboard with three containers; cards.

Description: Learners received cards representing (1) mom, dad, teachers, friends etc. as the persons who the learners make their homework with, (2) kitchen, living room etc. as the places where learners make their homework, and (3) 1 hour, 2 hours, 3 hours etc., referring to the time that learners spend on their homework everyday. Learners were then asked to put the cards with their responses into the containers.

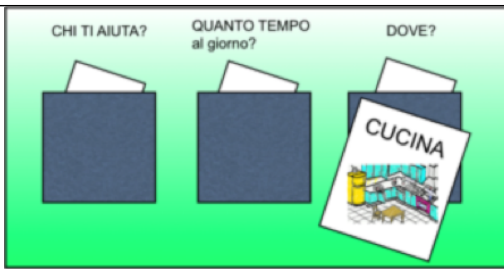

\section{B. Experiment Execution}

The field study sessions were conducted during May, 2011. We visited each school for 1 or 2 days, depending on the number of classes in the study, having in total 15 primary school classes with children of all ages. In each class, we

Table VI

AN OVERVIEW OF THE LEARNERS PARTICIPATING IN THE FIELD STUDY.

\begin{tabular}{|c|c|c|c|}
\hline School & Class & Deaf/hearing & $\begin{array}{c}\text { \# of } \\
\text { Learners }\end{array}$ \\
\hline Primary school, Torre di Mosto & 3 & Hearing & 42 \\
\hline Institute Gramsci Campalto & 3 & Hearing & 16 \\
& 3 & Deaf & 1 \\
\hline Pescasseroli & 2 & Hearing & 20 \\
& 3 & Hearing & 21 \\
& 4 & Hearing & 17 \\
& 5 & Hearing & 19 \\
\hline Masseri Avezzano & 2 & Hearing & 35 \\
& 3 & Hearing & 38 \\
& 4 & Hearing & 18 \\
& 5 & Hearing & 16 \\
\hline San Demetrio ne' Vestini (AQ) & 6 & Hearing & 37 \\
\hline
\end{tabular}


Table VII

AN OVERVIEW OF PARTICIPATING LEARNERS, PER AGE, GENDER AND HEARING VERSUS DEAF.

\begin{tabular}{|c|c|c|c|c|}
\hline & & \multicolumn{3}{|c|}{ \# of } \\
\cline { 3 - 5 } Class & Hearing/Deaf & Learners & Boys & Girls \\
\hline 2 & Hearing & 55 & 23 & 32 \\
3 & Hearing & 117 & 54 & 63 \\
4 & Hearing & 35 & 21 & 14 \\
5 & Hearing & 35 & 16 & 19 \\
6 ("1media") & Hearing & 37 & 23 & 14 \\
3 & Deaf & 1 & 0 & 1 \\
\hline
\end{tabular}

spent about 90 minutes with learners, and each class teacher participated in a 20-minute interview. All tasks described in Sect. [II-A were done with all the learners. We then collected all assignments and stored the interviews with teachers.

\section{Result Analysis and User Classes}

In order to specify user classes, we used personas [5]. In the following, for space limitation, we only describe the quantitative analysis of data for the learners. More details on the result analysis are in [4].

1) Data Management: all data gathered using the assignments described in the experiment design section (Sect. [I-A) is stored in a database for quantitative analysis.

2) Statistics: statistics of the quantitative data were calculated using $\chi^{2}$ and Fisher's analysis. Natural variables like gender and age were defined. Other dichotomy variables were derived from statistics observations 1

3) Data Analysis: graphics describing the variables associations were depicted. Using these data, we derived a first classification that stems from orthogonal dimensions (e.g., North/Centre) and sorts learners according to opposite dimensions, or dichotomies.

4) User Classes: using tables, graphics and variables associations, we derived five different classes, obtained by excluding some others based on the behaviour of variables associations:
a) deaf female;
b) hearing female;
c) 7-9 old hearing rural male from the North of Italy;
d) 7-9 old hearing rural male from the Centre of Italy;
e) 9-11 old hearing urban male from the Centre of Italy.

\section{The TERENCE Personas}

A persona per user class was created and allowed us to share the information concerning the analysis among all the members of the TERENCE heterogeneous consortium, and pass on the relevant information to the designers for the definition of the use cases of the ALS. Fig. 1 describes the persona for the deaf female class, as an example. All the other personas are structured in the same manner.

\footnotetext{
${ }^{1}$ It is worth noting that only one deaf learner was found in the field study, and thus the results may not be reliable for this dimension.
}

\begin{tabular}{|c|c|}
\hline \multicolumn{2}{|r|}{ Characteristics } \\
\hline Q⿻日木 & $\begin{array}{l}\text { Persona Name: Carla. } \\
\text { Age: } 11 . \\
\text { Gender: Female. } \\
\text { Classroom: III. } \\
\text { Comprehension skill: Poor Comprehender. } \\
\text { Deaf/hearing: Deaf. }\end{array}$ \\
\hline $\begin{array}{l}\text { Summary of the class } \\
\text { represented by this } \\
\text { persona }\end{array}$ & $\begin{array}{l}\text { Represents the class of children aged between } 7 \text { and } 11 \text { years old. } \\
\text { Deaf belonging to an Italian school. Has passion for drawing. She } \\
\text { writes every day in her secret diary. Good use of technologies for } \\
\text { research on Internet. }\end{array}$ \\
\hline Personality & She is polite and quiet. \\
\hline Role in classroom & She is active, careful, and diligent. \\
\hline Role out of the class & She is nice, responsible and kind. \\
\hline Console/Technology & $\begin{array}{l}\text { She plays with the Nintendo WII and DS; she uses the computer } \\
\text { to browse and chat with friends. She uses the technology alone. }\end{array}$ \\
\hline $\begin{array}{l}\text { Socio-Cultural Level of } \\
\text { his/her own family }\end{array}$ & High. \\
\hline School performance & $\begin{array}{l}\text { She learns very easily. Differently than } 2 \text { years ago, her level of } \\
\text { frustration is increased with age. }\end{array}$ \\
\hline \multicolumn{2}{|r|}{ Environment } \\
\hline Time spent with family & $\begin{array}{l}\text { She does her homework with her parents, she spends her time } \\
\text { with her mother and she draws and reads stories with her father. }\end{array}$ \\
\hline Time spent with friends & $\begin{array}{l}\text { She meets her cousin every day to do homework or to play with } \\
\text { her. She goes out with her friends after her homework. }\end{array}$ \\
\hline Homework & She does her homework in the afternoon supported by parents. \\
\hline \multicolumn{2}{|r|}{ Life style } \\
\hline Outdoors Activities & $\begin{array}{l}\text { She likes to see friends regularly, she likes to going out and plays } \\
\text { with her dog, and she likes to do shopping with her grandmother. }\end{array}$ \\
\hline Indoors Activities & $\begin{array}{l}\text { She plays with Nintendo WII, and DS, She read, writes, and } \\
\text { draws. She likes to play with her cousin. }\end{array}$ \\
\hline Home activities & $\begin{array}{l}\text { She read fairy tales with dad, she watch TV and she chat with her } \\
\text { friends. }\end{array}$ \\
\hline Sport activities & She loves walking and cycling with her mom. \\
\hline
\end{tabular}

Figure 1. One of the TERENCE personas

\section{Global SyStem ARChitecture}

Starting from the results of the context of use analysis and requirements, we designed the conceptual model of the ALS, and hence the global system architecture, see Fig. 2 The system is a Java web application, running on a web application server and accessed by users via standard web browsers. This choice of design was made to ensure that the system is accessible to the users at any time and from everywhere (at school and at home) and independent on the platform and operating system of the used device. The system provides three GUIs, one for each type of the system end users: learner GUI, educator GUI and expert GUI.

In order to ensure a modular and extensible design of the system design, the different functionalities of the system are provided by different components, which are integrated in a service-oriented architecture.

On the data layer we have the storage components, for storing the data about the users and the learning resources. 


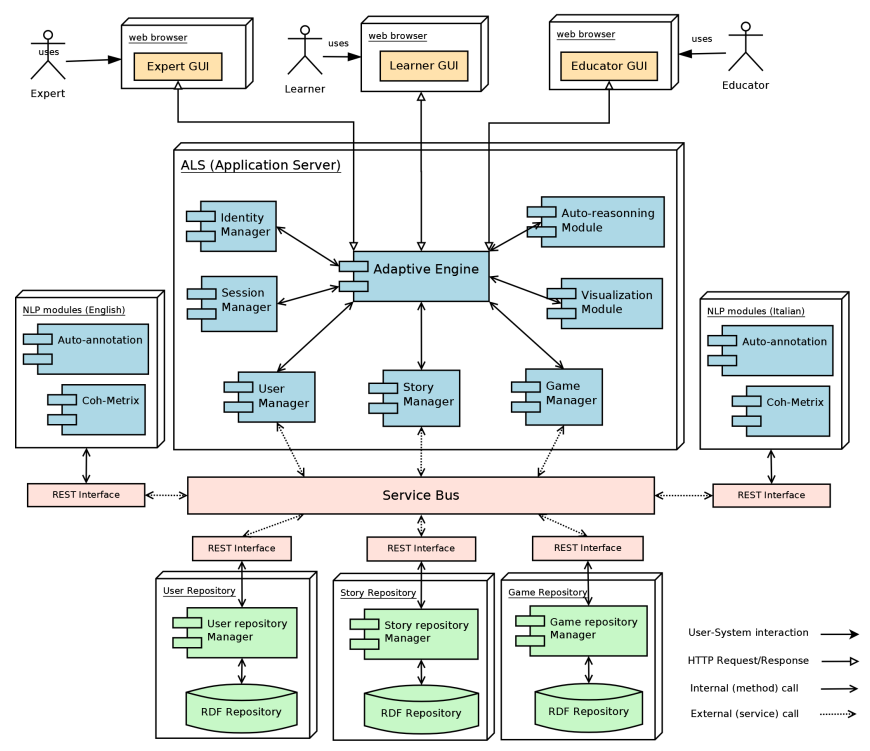

Figure 2. Architecture

In particular, the system uses a user repository, a story repository and a game repository. Each of these repositories has a repository manager for managing communication between the repository and the rest of the system. Repositories are exposed as services and, therefore, provides an appropriate web service interface.

On the application layer we have the ALS. The ALS consists of several components. There are three data management components: 1) user manager for managing users' data including learners' profile; 2) story manager for managing the content and metadata of books and stories; 3) game manager for managing the content and metadata of games. The core adaptation functionalities of the ALS are encapsulated in the adaptive engine component such as providing access to the stories and providing access to the games. This includes automatic recommendation and adaptation of the provided resources to the specific class of learners and based on their interaction with the system.

The adaptive engine is complemented with a set of other components. The visualisation component is responsible for managing the presentation of the materials (e.g. stories and games) as well as the different types of GUIs. The Natural Language Processing (NLP) component is used to analyse the text of the stories and annotate the key concepts such as characters, events, temporal relations etc. The reasoning component is responsible for reasoning about the stories using the annotations produced by the NLP component and providing classes of learners with useful feedback on their performance with the games.

\section{Reading Stories or Playing Games with CARLA}

Given the user classes presented in Sect. III and the architecture in Sect. III], the section aims at showing how concretely how Carla, personified as in Fig. 11, reads the TERENCE stories and interacts with the stories' games by means of a key use case for her. To keep the presentation as simple and yet as general as possible, the following use case mainly describes features common to Carla and all the other TERENCE personas, even if the description mentions Carla and some of her specific requirements.

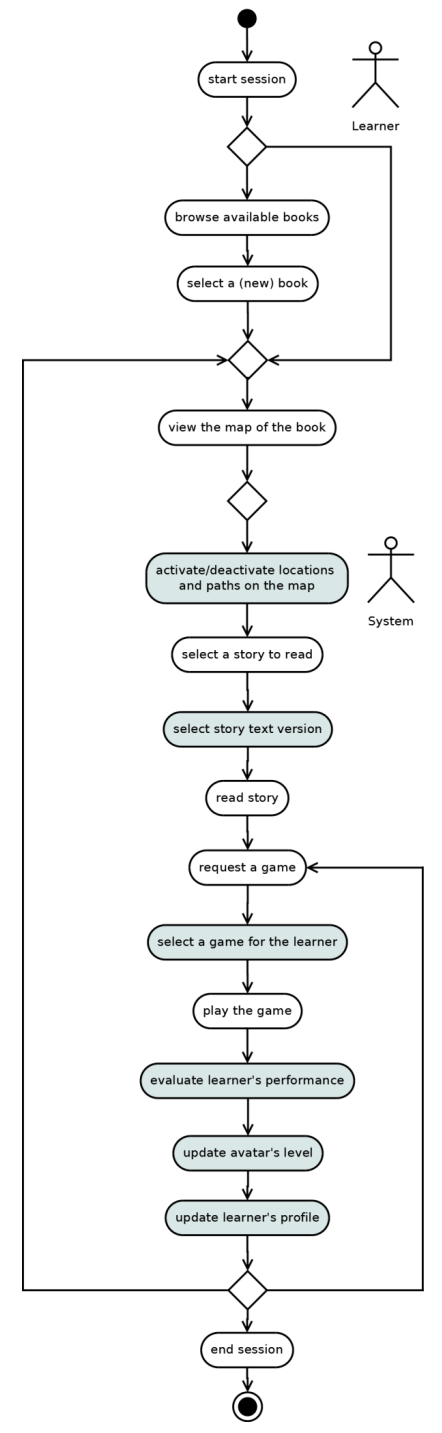

Figure 3. Activity diagram of the reported use-case

Fig. 3 represents the different steps in this interaction process. At the beginning of a reading session, Carla either selects a previously opened book or browses the directory of available books. Since Carla prefers fairy tales, the system first shows fairy tale books. Carla selects one of the unread 
ones and a visual metaphor map of the selected book is displayed, see Fig. 4 The map contains locations or objects that represent the stories of the book (for example, a castle or a forest). Each time Carla accesses the map, and depending on Carla's profile, the system decides the level of difficulty of the stories Carla should have access to, e.g., based on some adaptation rules or a pre-defined stimulation plan created by an educator. The ALS guides Carla by activating or deactivating the visual representations of the stories and the paths between them. Carla has then the possibility to select one of the activated stories and to start reading it. After reading the story, Carla plays the games associated to it. The sequence, type and difficulty level of the games is decided by the adaptive engine of the system and is based on Carla's profile as well as Carla's performance in the games. In particular, since her level of frustration is high, the most difficult text-comprehension games are often alternated by relaxing games, i.e., those that stimulate visuo-perception and she is best at. The performance of Carla also influences the assessment of Carla's reading comprehension, which leads to updating Carla's profile. In addition, and to help keep low Carla's level of frustration, Carla has a visual avatar that accompanies her during the learning process life. A good performance in the games of the story leads to upgrading the avatar in terms of gaining more attributes and accessories.

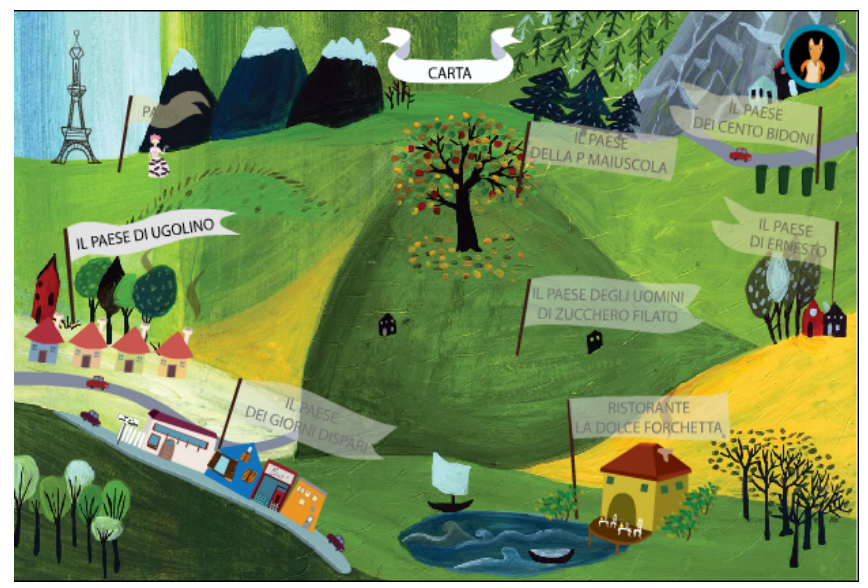

Figure 4. The map of a book

\section{Conclusion And Future Works}

In this paper, we described how the UCD-based context of use and requirements analyses allowed us to create user classes, personas, and hence use cases for the TERENCE ALS architecture. Currently, we are working on a finergrained analysis of the user requirements, to be reviewed through small-scale evaluations. The updated requirements will provide the input for the revision of the conceptual model of the TERENCE ALS, in particular, its user model, and hence the final implementation of the TERENCE software. Such evaluations, more in general, will serve to assess the usability of our ALS, and in particular: (1) the appeal and adequacy of its learning material, (2) the pedagogical effectiveness of our ALS in improving the text comprehension of 7-11 old poor comprehenders.

Acknowledgments The authors' work was supported by the TERENCE project, funded by the EC through the FP7 for RTD, Strategic Objective ICT-2009.4.2, ICT, TEL. The contents of the paper reflects only the authors' view and the $\mathrm{EC}$ is not liable for it. The work was also funded by the CRESCO and DARE projects, financed by the Province of Bozen-Bolzano.

Note The order of authors is alphabetical.

\section{REFERENCES}

[1] M. Alrifai, R. Gennari, O. Tifrea, and P. Vittorini. The Domain and User Models of the TERENCE Adaptive Learning System. In Proc. of eb-TEL 2012, Springer, 2012.

[2] M. Alrifai, R. Gennari, and P. Vittorini. Adapting with Evidence: the Adaptive Model and the Stimulation Plan of TERENCE. In Proc. of eb-TEL 2012. Springer, 2012.

[3] P. Brusilovsky. Adaptive Hypermedia: From Intelligent Tutoring Systems to Web-Based Education. In Lecture Notes In Computer Science, , 5th international Conference on intelligent Tutoring Systems, 2000.

[4] T. Di Mascio, R. Gennari, A. Melonio, and P. Vittorini. The User Classes Building Process in a TEL project. In Proc. of eb-TEL 2012, Springer, 2012.

[5] G. D. Gasperis, T. D. Mascio, and N. Florio. TATOT: a Viewer for Annotating Stories in the TERENCE Project. In Proc. of ITAIS 2011, 2011.

[6] J. Goransson, B. Boivie, I.Blomkvist, S. Persson, and J. Cajanger. Key principles for user-centred systems design. Behavior and Information Technology, 22(6):397-409, 2003.

[7] H. Hartson, T. Andre, and R. Williges. Criteria for Evaluating Usability Evaluation Methods. International Journal of Human Computer Interaction, 13(4):373-410, 2001.

[8] T. D. Mascio and R. Gennari. Integrating Usability Engineering for Designing the Web Experience: Methodologies and Principles, chapter A Usability Guide to Intelligent Web Tools for the Literacy of Deaf People, pages 201-224. ICI Global, 2010.

[9] M. Pasini. Working Document 1.1: User Classification and Identification. Technical report, TERENCE project, 2011.

[10] K. Slegers and R. Gennari. State of the Art of Methods for the User Analysis and Description of Context of Use. Technical Report D1.1, TERENCE project, 2011.

[11] K. Slegers and T. D. Mascio. Working Document 1.2: Usability goals and User needs. Technical report, TERENCE project, 2011. 